Article

\title{
A Statistical Study on the Effect of Hydrostatic Pressure on Metastable Pitting Corrosion of X70 Pipeline Steel
}

\author{
Zixuan Yang ${ }^{1}$, Bo Kan ${ }^{1}$, Jinxu Li ${ }^{1, *}$, Yanjing Su ${ }^{1}$, Lijie Qiao ${ }^{1}$ and Alex A. Volinsky ${ }^{2}$ \\ 1 Corrosion and Protection Center, Key Laboratory for Environmental Fracture (MOE), \\ University of Science and Technology Beijing, Beijing 100083, China; Zixuan_Yang2017@163.com (Z.Y.); \\ Kanbo10008@163.com (B.K.); yjsu@ustb.edu.cn (Y.S.); lqiao@ustb.edu.cn (L.Q.) \\ 2 Department of Mechanical Engineering, University of South Florida, Tampa, FL 33620, USA; \\ volinsky@usf.edu \\ * Correspondence: jxli65@ustb.edu.cn; Tel.: +86-010-6233-4493
}

Received: 28 September 2017; Accepted: 10 November 2017; Published: 14 November 2017

\begin{abstract}
Hydrostatic pressure effects on pitting initiation and propagation in X70 steel are investigated by evaluating metastable pitting probability using electrochemical methods and immersion corrosion tests in containing chlorine ion solution. Potentiodynamic tests indicated that hydrostatic pressure can decrease the breakdown potential and lead to a reduced transpassivity region. Metastable test results revealed that hydrostatic pressure can increase metastable pitting formation frequency and promote stabilization of metastable pitting growth. Electrochemical impedance spectroscopy (EIS) results indicate that Hydrostatic pressure decreases the charge transfer resistance and increases the dissolution rate within the cavities. Corrosion test results also indicated that pitting initiation and propagation are accelerated by hydrostatic pressure. Result validity was verified by evaluating metastable pitting to predict pitting corrosion resistance.
\end{abstract}

Keywords: X70 steel; SEM; scanning kelvin probe force microscopy (SKPFM); hydrostatic pressure; potentiostatic; pitting corrosion

\section{Introduction}

There are significant amounts of resources in the deep ocean, including oil, gas and valuable minerals. The deep sea is a complex environment, subjecting materials to high hydrostatic pressure. Materials face huge challenges in the deep-sea environment [1]. X70 pipeline steel is used for deep sea oil exploration and recovery. Stress corrosion cracking (SCC) and corrosion significantly effect pipeline steel life. Usually, corrosion and SCC of pipeline steel originate from pitting corrosion. Thus, it is necessary to evaluate pitting susceptibility of the X70 pipeline steel in the deep sea environment.

Pitting corrosion initiation and propagation can be affected by microstructure, chemical composition and the environment [2,3]. Hydrostatic pressure may change metal electrochemical behavior due to environmental effects [4-11]. Beccaria et al. [4-8] studied the effects of hydrostatic pressure on corrosion behavior of passive metals using a pressure vessel. They found that the pitting susceptibility of $\mathrm{Ni}$ and $\mathrm{Al}$ increased with hydrostatic pressure. Zhang et al. [9] reported that pitting susceptibility of stainless steel deteriorated with hydrostatic pressure. Yang et al. [10,11] reported that high hydrostatic pressure accelerated pit growth rate in $\mathrm{Ni}-\mathrm{Cr}-\mathrm{Mo}-\mathrm{V}$ steel. While previous studies focused on passive metals, there are only a few fundamental reports of the hydrostatic pressure effects on pitting of active metals. However, the hydrostatic effects on the steel corrosion mechanism is not clear.

Pitting corrosion is characterized by the three steps of pit initiation, metastable propagation and stabilization [12]. Metastable pitting is an important factor to evaluate pitting corrosion. Many 
researchers have studied metastable pitting to predict pitting tendency and propagation rate [13-20]. Amin et al. [17] studied metastable pitting events in $\mathrm{Al}$ and found that metastable pitting potential $\left(\mathrm{E}_{\mathrm{m}}\right)$ is proportional to the pitting potential $\left(\mathrm{E}_{\mathrm{p}}\right)$. Tian et al. reported that metastable pitting lifetime, current peak value and nuclei frequency increased with increasing potential in stainless steel [3]. Gholami et al. studied grain size effects on pitting by evaluating metastable pitting events [16]. Guan et al. predicted cyclic stress effects on pitting by studying metastable pitting of stainless steel [15]. Many previous reports had focused on metastable pitting behavior of passive metals. However, X70 steel is an active metal, and pitting corrosion performance of carbon steel is likely to be completely different from passive metals [21,22].

In this work, hydrostatic pressure effects on pitting corrosion initiation and propagation of X70 pipeline steel were studied by evaluating metastable pitting events using electrochemical methods in $0.5 \mathrm{~mol} / \mathrm{L} \mathrm{NaHCO}_{3}+0.1 \mathrm{~mol} / \mathrm{L} \mathrm{NaCl}$ solution. Statistical measurements of metastable pits characteristics were performed by using the potentiostatic method to obtain useful information about the pitting initiation and stabilization. To verify the potentiostatic method accuracy, immersion corrosion experiments were also performed in $0.1 \mathrm{~mol} / \mathrm{L} \mathrm{NaCl}$ solution.

\section{Experimental Methods}

\subsection{Materials and Sample Preparation}

X70 pipeline steel is used in this experiment. Chemical composition of the steel is listed in Table 1. Specimens were not heat treated before the tests.

Table 1. Chemical composition of the X70 steel specimens (wt \%).

\begin{tabular}{cccccccccc}
\hline $\mathbf{C}$ & $\mathbf{S i}$ & $\mathbf{M n}$ & $\mathbf{C r}$ & $\mathbf{N i}$ & $\mathbf{T i}$ & $\mathbf{V}$ & $\mathbf{N b}$ & Others & $\mathbf{F e}$ \\
\hline 0.066 & 0.29 & 1.39 & 0.032 & 0.20 & 0.015 & 0.037 & 0.056 & 0.300 & Bal. \\
\hline
\end{tabular}

Small specimens for potentiostatic and potentiodynamic polarization tests with $2 \times 2 \times 5 \mathrm{~mm}$ size were cut from the X70 plates. The non-working surface of the specimen was sealed with silica gel. Standard corrosion specimens $(10 \mathrm{~mm} \times 10 \mathrm{~mm} \times 5 \mathrm{~mm})$ were used for corrosion tests. Working face of the specimens was sanded by emery paper from 400 to 5000 number and then the specimens were polished with $1 \mu \mathrm{m}$ diamond paste. Finally, the specimens were ultrasonically cleaned in ethanol [23].

\subsection{Electrochemical Measurements during Hydrostatic Pressure Loading}

Experiments were carried out in a pressure vessel, where pressure was changed, while other parameters were kept constant. Temperature was controlled by a thermostatic bath at $25^{\circ} \mathrm{C}$. Solution was kept air saturated with oxygen at $5 \mathrm{mg} / \mathrm{L}(\mathrm{ppm})$ concentration, which was the same at $0.1 \mathrm{MPa}$.

Electrochemical measurements were carried out in $0.5 \mathrm{~mol} / \mathrm{L} \mathrm{NaHCO}_{3}+0.1 \mathrm{~mol} / \mathrm{L} \mathrm{NaCl}$ solution using Gamry electrochemical workstation (Gamry, Reference 6000, Warminster, PA, USA). The solution was prepared using analytical grade chemicals and deionized water. This solution was used because it is gentler than the $3.5 \% \mathrm{NaCl}$ solution to investigate the corrosion process. Electrochemical experimental device was comprised of three electrodes system. The counter electrode was platinum foil and the reference electrode was $\mathrm{Ag} / \mathrm{AgCl}$ electrode.

During potentiodynamic polarization measurements, the potential was scanned from $-360 \mathrm{mv}$ vs. $\mathrm{Ag} / \mathrm{AgCl}$ electrode. Potential scanning rate was kept at $0.2 \mathrm{mV} / \mathrm{s}$ to anodic direction until stable pitting occured. Data acquisition rate was $20 \mathrm{~Hz}$ and no data smoothing were applied [13].

Samples were potentiostatically polarized at $-100 \mathrm{mV}$ vs. $\mathrm{Ag} / \mathrm{AgCl}$ electrode for $2000 \mathrm{~s}$ and at the same time the current response was recorded at $20 \mathrm{~Hz}$ frequency. Current peak value of $20 \mathrm{nA}$ was defined as the critical value of a metastable event. The morphology of potentiostatically polarized 
samples was observed by scanning electron microscopy (SEM). Each electrochemical measurement was repeated 3 times under the same conditions.

Electrochemical impedance spectroscopy (EIS) tests during immersion test were conducted at a frequency ranging from $0.01 \mathrm{~Hz}$ to $100 \mathrm{kHz}$ with a $5 \mathrm{mV}$ amplitude signal at open circuit potential.

\subsection{Stable Pit Propagation Measurements}

To verify hydrostatic pressure effects on stable pitting growth and ensure potentiostatic method validity, immersion corrosion tests were conducted in $0.1 \mathrm{~mol} / \mathrm{L} \mathrm{NaCl}$ solution at $0.1 \mathrm{MPa}, 5 \mathrm{MPa}$ and $10 \mathrm{MPa}$ for $30 \mathrm{~min}$, respectively. 3D profiles of typical corrosion pitting on the X70 steel surface after $30 \mathrm{~min}$ immersion at different hydrostatic pressure in $0.1 \mathrm{~mol} / \mathrm{L} \mathrm{NaCl}$ solution were measured by confocal scanning laser microscope (Olympus, LEXT 3100, Tokyo, Japan) [11].

\subsection{Microstructure Characterization}

The inclusions in X70 pipeline steel were observed by SEM. Chemical composition of inclusions were analyzed with energy dispersive spectra (EDS) attached to an SEM (Zeiss, EVO MA10/LS 10, Oberkochen, Germany).

\section{Results}

Our previous work had reported that there are three inclusions types in the X70 steel. Type A inclusion is complex, consisting of two parts. One part of the inclusion is rich in $\mathrm{Mn}, \mathrm{Ca}$ and $\mathrm{S}$, while the other part is rich in $\mathrm{Al}, \mathrm{Ca}$ and $\mathrm{O}$. Two parts of Type $\mathrm{A}$ inclusion can be clearly distinguished based on the morphology. Type $\mathrm{B}$ inclusion is only rich in $\mathrm{Al}, \mathrm{Ca}$ and $\mathrm{O}$, while type $\mathrm{C}$ inclusion is only rich in $\mathrm{Mn}, \mathrm{Ca}$ and S [24].

\subsection{Metastable Pitting Analysis}

Previous workers had focused on metastable pitting behavior of passive metals [16-18]. However, we will study the metastable pitting behavior of active X70 steel. Figure 1 shows potentiodynamic polarization curves of the $X 70$ steel obtained with $0.2 \mathrm{mV} / \mathrm{s}$ scanning rate in $0.5 \mathrm{~mol} / \mathrm{L} \mathrm{NaHCO}_{3}+0.1 \mathrm{~mol} / \mathrm{L} \mathrm{NaCl}$ solution at atmospheric pressure. The potentiodynamic polarization test was stopped at the region between metastable pitting potential $E_{m}$ and $E_{p}$. Morphology of metastable pitting at inclusion sites after potentiodynamic polarization test was studied by SEM. Pits were clearly generated at the inclusion positions. Passive film of the type A inclusion had been broken at the site richer in $\mathrm{Mn}, \mathrm{Ca}$ and $\mathrm{S}$, while passive film of the type B inclusion is intact. Passive film of the type $\mathrm{C}$ inclusion had been broken through and the inclusion was partially dissolved. Passive film of types $A$ and $C$ inclusions are easier to be broken through than the metal matrix surface. This result indicated that type $\mathrm{A}$ and $\mathrm{C}$ inclusion can induce metastable pits and type $\mathrm{B}$ inclusion cannot induce metastable pits at the passive range of passive region. Metastable pits were generated at the active inclusions positions. Thus, type $A$ and $C$ is active inclusions and type $B$ is not active inclusion [24].

\subsection{Electrochemical Results}

\subsubsection{Potentiodynamic Polarization Curves}

Potentiodynamic curves of the X70 pipeline steel at $0.1 \mathrm{MPa}, 5 \mathrm{MPa}$ and $10 \mathrm{MPa}$ are shown in Figure 2. Current fluctuations were observed in the passive region during potentiodynamic test. Current fluctuations can be regarded as metastable pitting events. Figure 2 shows that the $\mathrm{E}_{\mathrm{pit}}$ of $0.1 \mathrm{MPa}$ at $8 \mathrm{mV} \mathrm{SCE}$ is higher than at $10 \mathrm{MPa}(-24 \mathrm{mV})$ in the $0.5 \mathrm{~mol} / \mathrm{L} \mathrm{NaHCO}_{3}+0.1 \mathrm{~mol} / \mathrm{L} \mathrm{NaCl}$ solution. Alloy pitting corrosion resistance increases with $\mathrm{E}_{\mathrm{pit}}$, this means that the $\mathrm{X} 70$ pipeline steel corrosion resistance is worsened by hydrostatic pressure. Furthermore, Figure 2 indicates that the passivity current density slightly increases with hydrostatic pressure. 


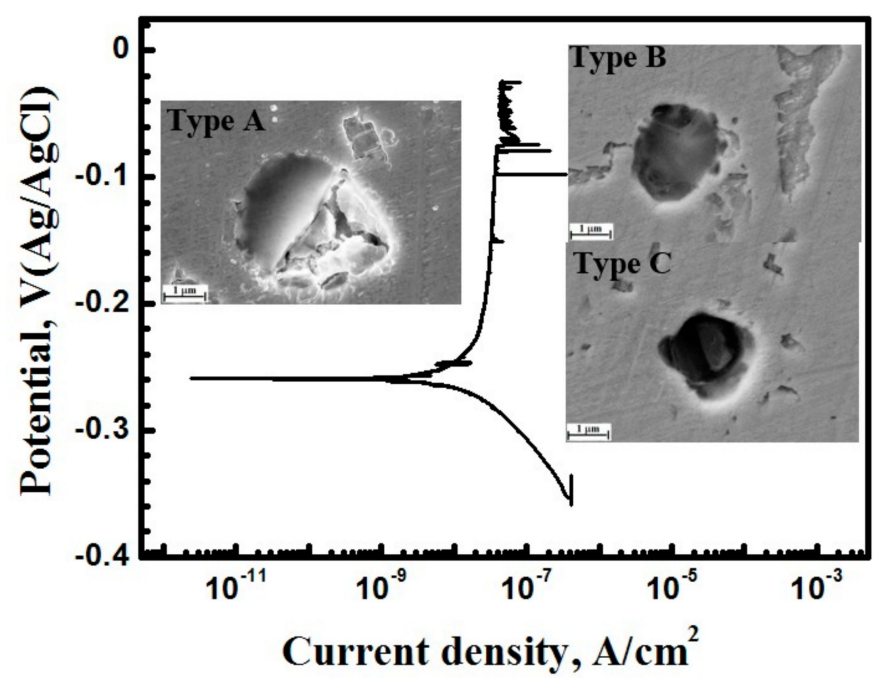

Figure 1. Slow scan rate potentiodynamic polarization curve and metastable pits morphology generated during the test in $0.5 \mathrm{~mol} / \mathrm{L} \mathrm{NaHCO}_{3}+0.1 \mathrm{~mol} / \mathrm{L} \mathrm{NaCl}$ solution.

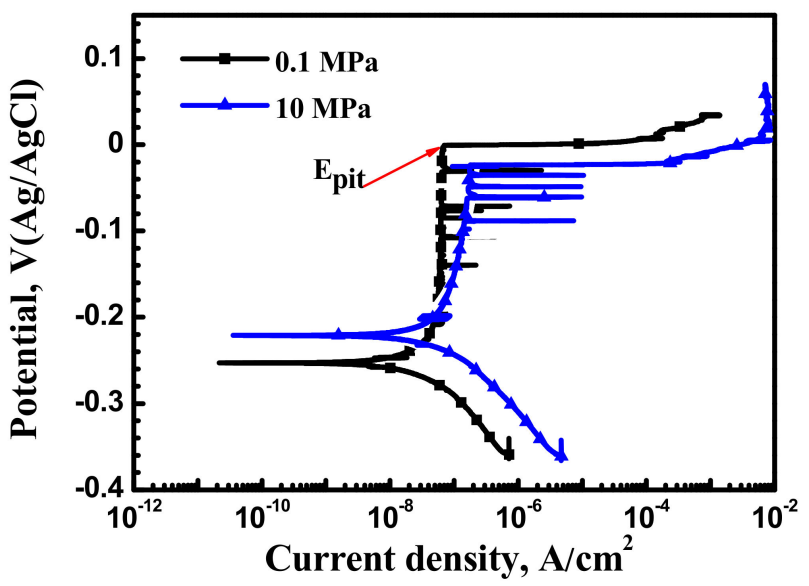

Figure 2. Polarization curves at $0.1 \mathrm{MPa}$ and $10 \mathrm{MPa}$ obtained with $0.2 \mathrm{mV} / \mathrm{s}$ scanning rate.

\subsubsection{Metastable Pitting Electrochemistry}

Stable pitting can develop from metastable pitting at the early stages [25], and stable pitting corrosion product is directly related to metastable pitting characteristics [24-26]. Potentiostatic measurements were carried out at constant potential to evaluate pitting initiation and stabilization from metastable pitting at different hydrostatic pressure.

Figure 3 shows time vs. current curves for the $X 70$ steel at $0.1 \mathrm{MPa}, 5 \mathrm{MPa}$ and $10 \mathrm{MPa}$ obtained with $-100 \mathrm{mV}$ vs. $\mathrm{Ag} / \mathrm{AgCl}$ electrode. Metastable pitting parameters were obtained and analyzed by statistical methods. Figure 4 shows local magnification of Figure 3 with typical current rise due to inclusion dissolution or abrupt passive film breakdown, followed by current quick decay corresponding to newly formed passive film. Metastable current transients do not increase to a high enough value, keeping stable pit growth. Current transient peak response shows local dissolution followed by repassivation.

Hydrostatic pressure affects the shape, size and frequency of current peaks in metastable pitting. Metastable current transients at different hydrostatic pressure can be described by maximum current $\left(\mathrm{i}_{\max }\right)$, peak current $\left(\mathrm{i}_{\text {peak }}\right)$, base current $\left(\mathrm{i}_{\mathrm{bc}}\right)$, pit growth time $\left(\mathrm{t}_{\mathrm{g}}\right)$ and repassivation time $\left(\mathrm{t}_{\mathrm{rp}}\right)$. Lifetime of a metastable pitting event is defined as, $t_{\text {pit }}=t_{g}+t_{r p}$. Peak current $\left(i_{\text {peak }}\right)$ is defined as, $i_{\text {peak }}=i_{\max }-i_{b c}$ [2]. These parameters are shown in Figure 4. 

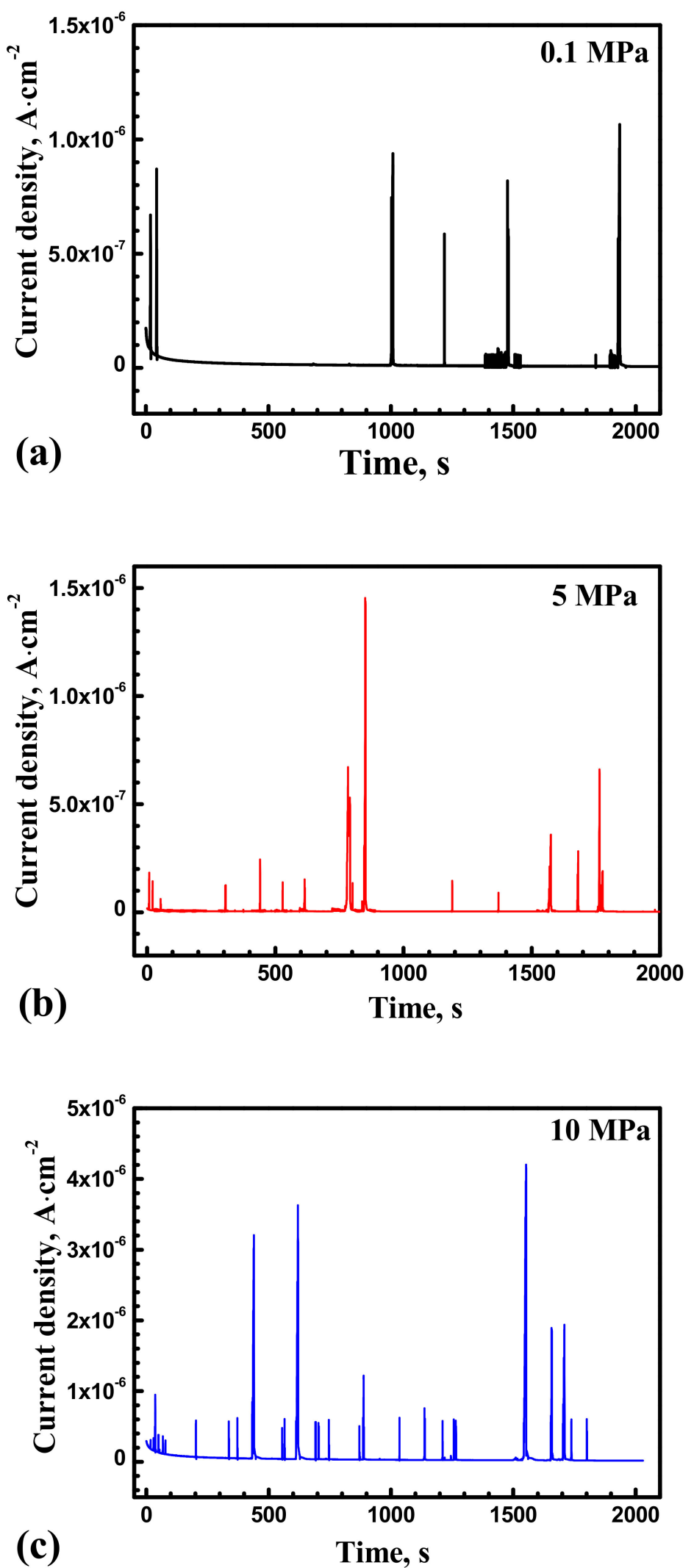

Figure 3. Typical current vs. time curves of the $X 70$ steel at various hydrostatic pressure in $0.5 \mathrm{~mol} / \mathrm{L}$ $\mathrm{NaHCO}_{3}+0.1 \mathrm{~mol} / \mathrm{L} \mathrm{NaCl}$ solution obtained under $-100 \mathrm{mV}$ vs. $\mathrm{Ag} / \mathrm{AgCl}$ electrode: (a) $0.1 \mathrm{MPa}$; (b) $5 \mathrm{MPa}$; (c) $10 \mathrm{MPa}$. 


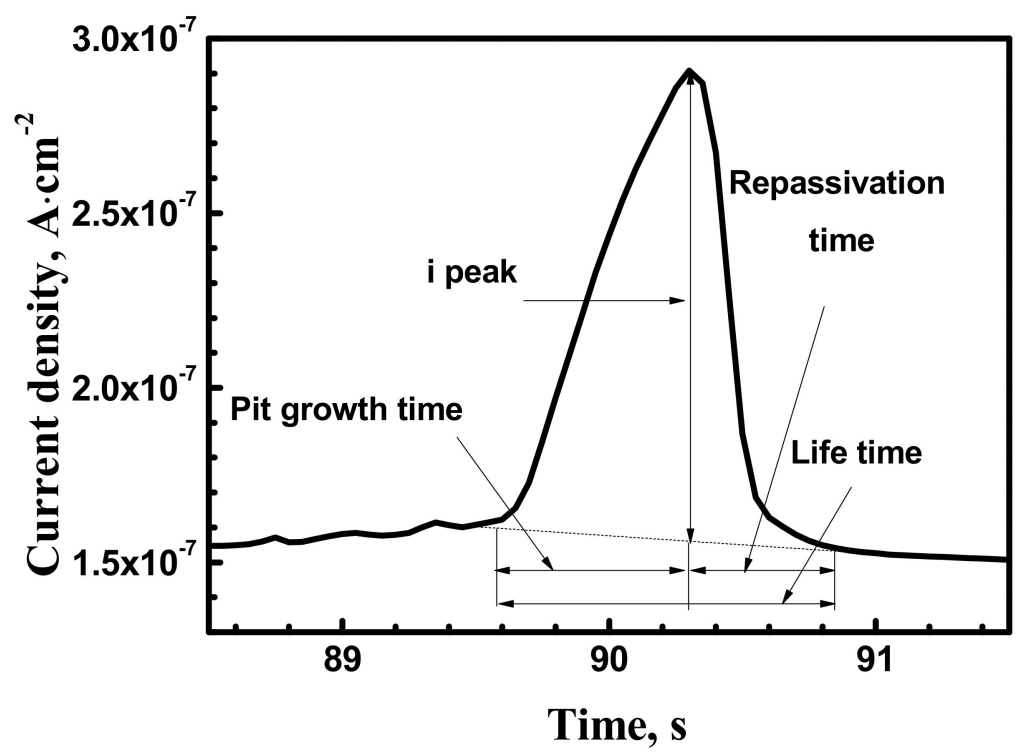

Figure 4. Typical shape of current transient in $0.5 \mathrm{~mol} / \mathrm{L}$ and $\mathrm{NaHCO}_{3}+0.1 \mathrm{~mol} / \mathrm{L} \mathrm{NaCl}$ solution at $-100 \mathrm{mV}$ vs. Ag/ AgCl electrode.

Figure 5 shows average metastable pit nucleation frequency $\lambda\left(\mathrm{cm}^{-2} \cdot \mathrm{s}^{-1}\right)$ for the X70 steel at various hydrostatic pressure with anodic potential $-100 \mathrm{mV}$ vs. $\mathrm{Ag} / \mathrm{AgCl}$ electrode. The $\lambda$ values were calculated by counting the number of events every $500 \mathrm{~s}$. Higher hydrostatic pressure causes an increase in the frequency of metastable pitting events. The nucleation frequency reduced with time due to elimination of pit nucleation sites from the electrode surface. In the first $500 \mathrm{~s}$, higher percentage of metastable pitting events was found. Metastable pitting frequency increase with hydrostatic pressure has been demonstrated. The result indicated that hydrostatic pressure makes many more metastable pits produce at inclusion sites. More inclusion can be activated by higher hydrostatic pressure.

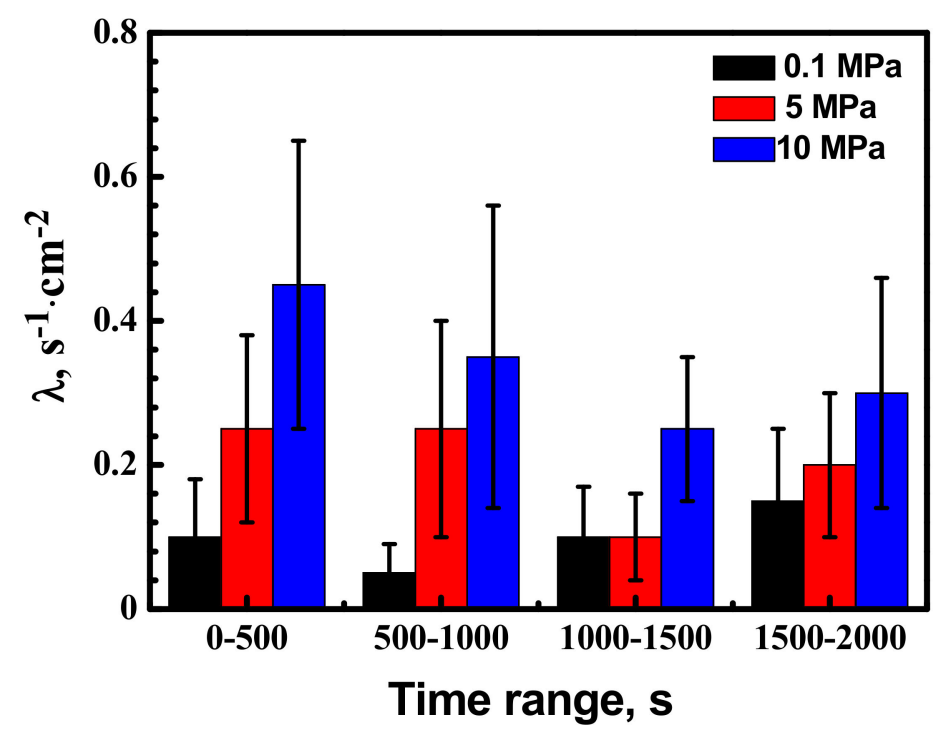

Figure 5. Metastable pit frequency in $0.5 \mathrm{~mol} / \mathrm{L} \mathrm{NaHCO}_{3}+0.1 \mathrm{~mol} / \mathrm{L} \mathrm{NaCl}$ aqueous solution for the X70 steel at various hydrostatic pressure and $-100 \mathrm{mV}$ vs. $\mathrm{Ag} / \mathrm{AgCl}$ electrode.

Lifetime is defined as the time between when metstable current transients begin to undergo repassivation initiation. Transient lifetime of metastable pit events at $0.1 \mathrm{MPa}, 5 \mathrm{MPa}$ and $10 \mathrm{MPa}$ is 
plotted in Figure 6. In this figure, the cumulative probability of the metstable pit lifetime was calculated as $n /(N+1)$ using a mean rank method [27], where $N$ is the total number of pits and $n$ is the order in the total number. There is an increase in metastable pitting lifetime with hydrostatic pressure. Long lifetime of metastable pitting means that inclusions are further dissolved and the repassivation is weak.

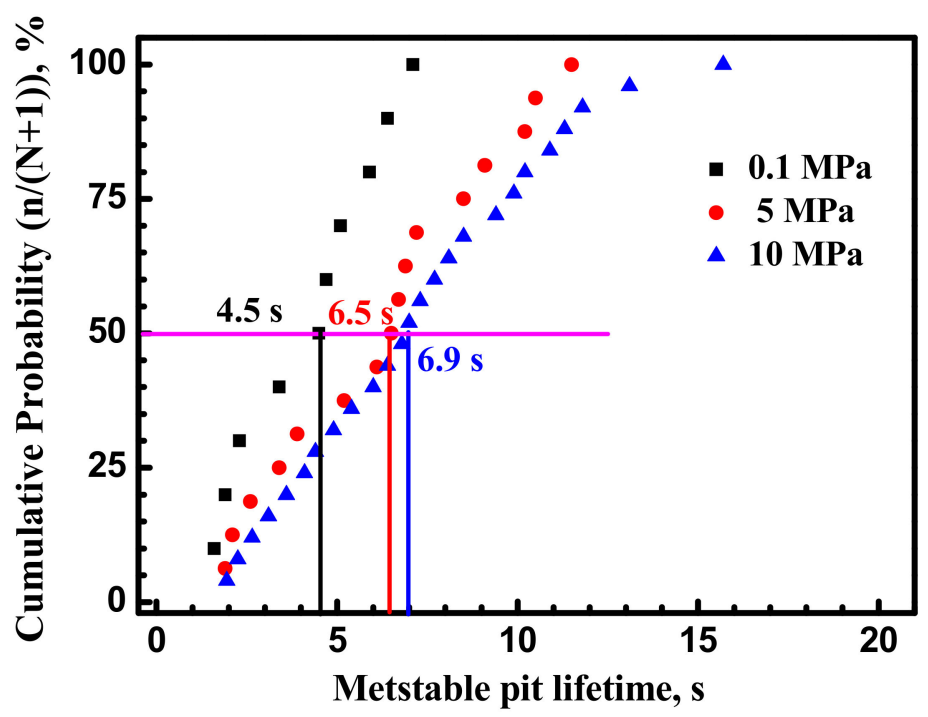

Figure 6. Cumulative distribution of metastable pits lifetime for the $\mathrm{X} 70$ steel at various hydrostatic pressures and $-100 \mathrm{mV}$ vs. $\mathrm{Ag} / \mathrm{AgCl}$ electrode.

Peak current $\left(\mathrm{i}_{\text {peak }}\right)$ is defined as, $\mathrm{i}_{\text {peak }}=\mathrm{i}_{\text {max }}-\mathrm{i}_{\mathrm{bc}}$. Figure 7 shows the value of peak current of metastable transients of the $X 70$ steel at various hydrostatic pressure and $-100 \mathrm{mV}$. The peak current $\left(\mathrm{i}_{\text {peak }}\right)$ will increase with hydrostatic pressure. X70 steel at $0.1 \mathrm{MPa}, 5 \mathrm{MPa}$ and $10 \mathrm{MPa}$ has the peak current $\left(\mathrm{i}_{\text {peak }}\right)$ values of $55.4 \mathrm{nA}, 68.1 \mathrm{nA}$ and $76.7 \mathrm{nA}$. Higher peak current indicated that many more active atoms were dissolved.

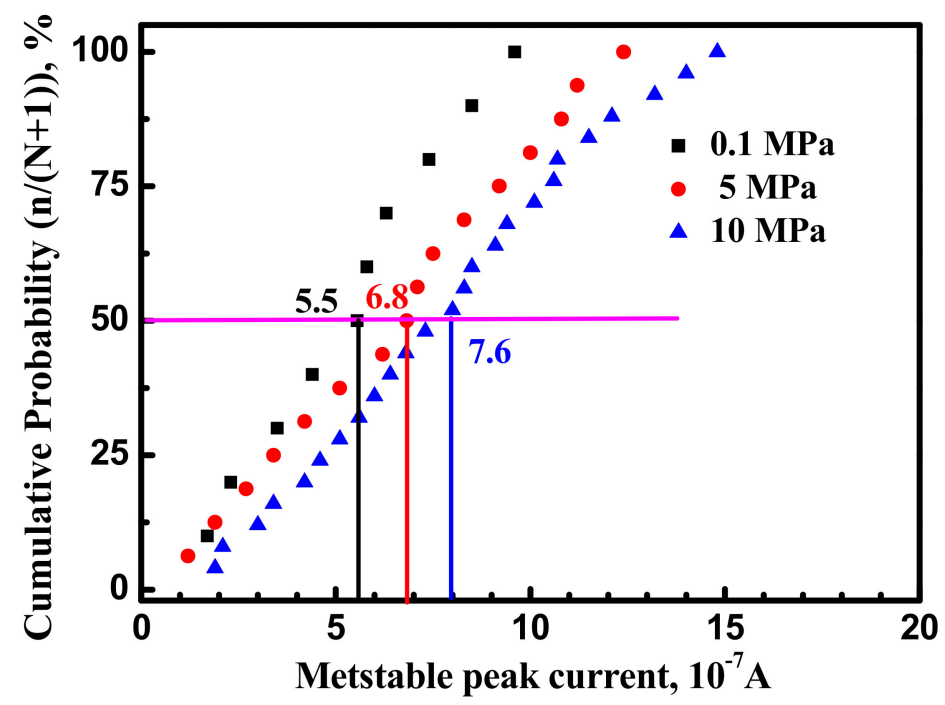

Figure 7. Cumulative distribution of metastable pits $i_{\text {peak }}$ for the $X 70$ steel at various hydrostatic pressure and $-100 \mathrm{mV}$. 
It is assumed that metastable pitting is hemispherical. Following Pistorius and Burstein [12,13], metastable pitting radius is calculated using the Faraday Equation [28,29]:

$$
r_{\text {pit }}=\left[\left(\frac{3 Z}{2 \pi \mathrm{n} F \rho}\right) \int_{t_{g}}^{t_{p}}\left(I_{\text {peak }}-I_{\text {org }}\right) \mathrm{dt}\right]^{1 / 3}
$$

Here, $\mathrm{Z}$ is the mean molecular weight of $55.2 \mathrm{mg} \cdot \mathrm{mol}^{-1}, \rho$ is the mean alloy density of $7.9 \mathrm{mg} \cdot \mathrm{cm}^{-3}$ and $F$ is the Faraday's constant. For the studied X70 steel it was assumed that the Fe element is oxidized to $\mathrm{Fe}^{2+}$ during corrosion. Hence, the oxidation state of cations (n) is considered to be 2 .

Figure 8 shows calculated radius of metastable pits using Equation (1) for the X70 steel at various hydrostatic pressure. Comparing the value of metastable pits radius, it can be seen that the metastable pits radius at $10 \mathrm{MPa}$ is larger than at $5 \mathrm{MPa}$ and at $0.1 \mathrm{MPa}$.

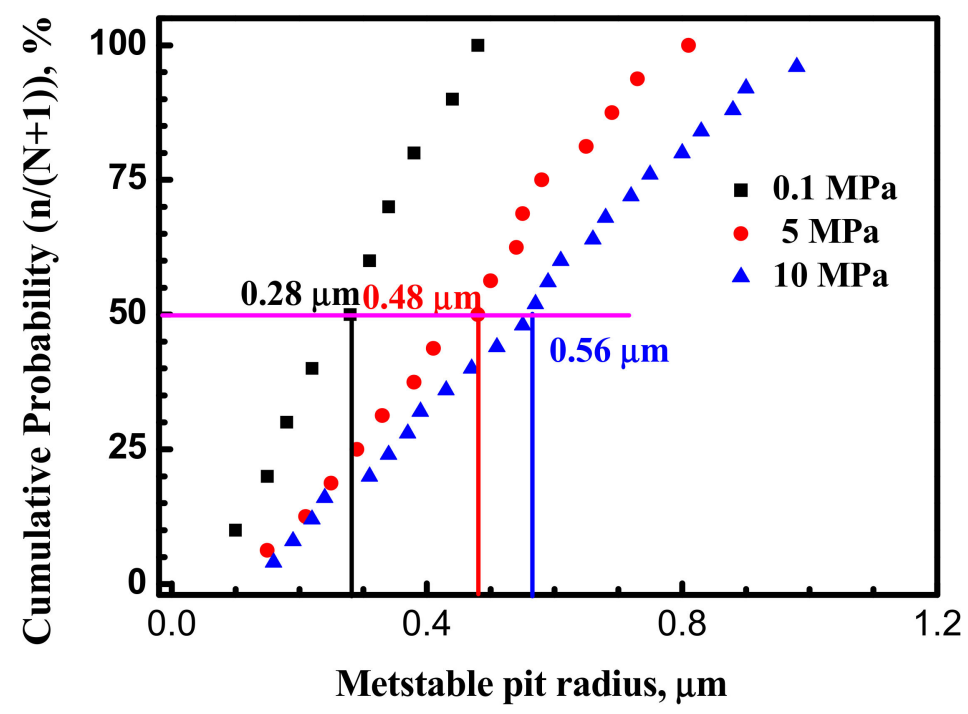

Figure 8. Cumulative distribution of metastable pits radius for the $\mathrm{X} 70$ steel at various hydrostatic pressure and $-100 \mathrm{mV}$ vs. $\mathrm{Ag} / \mathrm{AgCl}$ electrode.

Pit propagation is based on the diffusion criterion proposed by Pistorius and Burstein [1]. It is widely believed that stable pitting can transform from metastable pitting if the current density of metastable reaches the minimum and metastable pitting size is beyond the threshold value, $\mathrm{i}_{\text {peak }} \times \mathrm{r}_{\text {pit }}$ [15]. A metastable pit, which survived from the nucleation stage, grows unstably in the diffusion-controlled regime [13]. Rupture of corrosion products or inclusion dissolution promote anode dilution below the threshold current value, followed by repassivation, stopping metastable pit growth (for example type B inclusion). If the surface corrosion products rupture, promoting anode dilution above the critical current value, pit stabilization occurs (for example type $C$ inclusion). In the present work, the $i_{\text {peak }} \times r_{\text {pit }}$ values under various hydrostatic pressure are calculated, shown in Figure 9 . Comparing the average value of $i_{\text {peak }} \times r_{\text {pit }}$, it is evident that higher hydrostatic pressure results in higher pits stability. This means that hydrostatic pressure promotes metastable pitting propagation.

Corrosion morphology of the X70 steel immersed for $30 \mathrm{~min}$ in $0.1 \mathrm{~mol} / \mathrm{L} \mathrm{NaCl}$ solution at $0.1 \mathrm{MPa}$, $5 \mathrm{MPa}$ and $10 \mathrm{MPa}$ is shown in Figure 10. Confocal microscopy images of typical pits morphology of the X70 steel at different hydrostatic pressure are shown in Figure 11. Statistical distribution of the 3D pit size is plotted in Figure 12. 


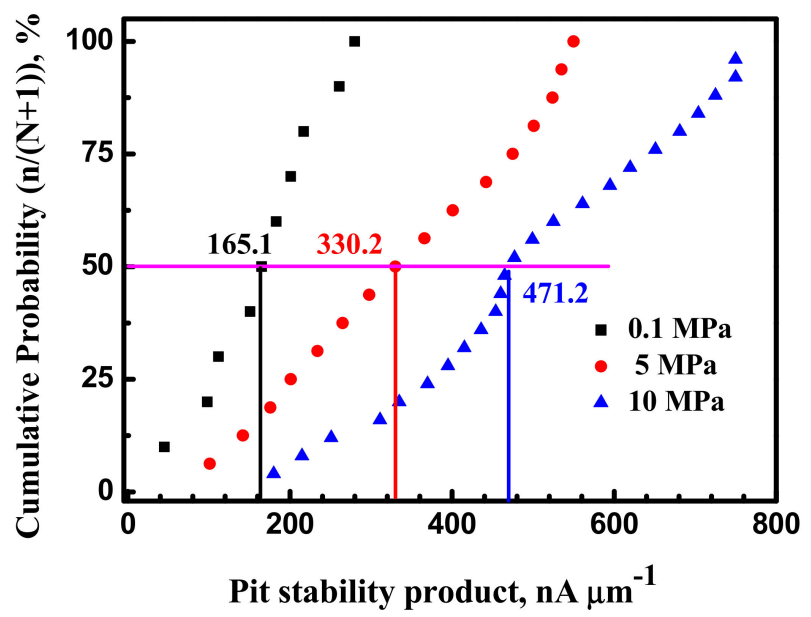

Figure 9. Cumulative distribution of metastable pits stability for the $\mathrm{X} 70$ steel at various hydrostatic pressure and $-100 \mathrm{mV}$ vs. $\mathrm{Ag} / \mathrm{AgCl}$ electrode.

By comparing corrosion morphology at different hydrostatic pressure, it is found that the X70 steel corrosion begins with generation of corrosion pitting and corroded area at $10 \mathrm{MPa}$ is larger than at $5 \mathrm{MPa}$ and $0.1 \mathrm{MPa}$. The number of pitting initiation sites at $10 \mathrm{MPa}$ is much larger than at $5 \mathrm{MPa}$ and $0.1 \mathrm{MPa}$. This implies that the pitting initiation is accelerated by hydrostatic pressure. This result is consistent with the value of metastable pits stability for the X70 steel. Hydrostatic pressure promotes pitting initiation and propagation.
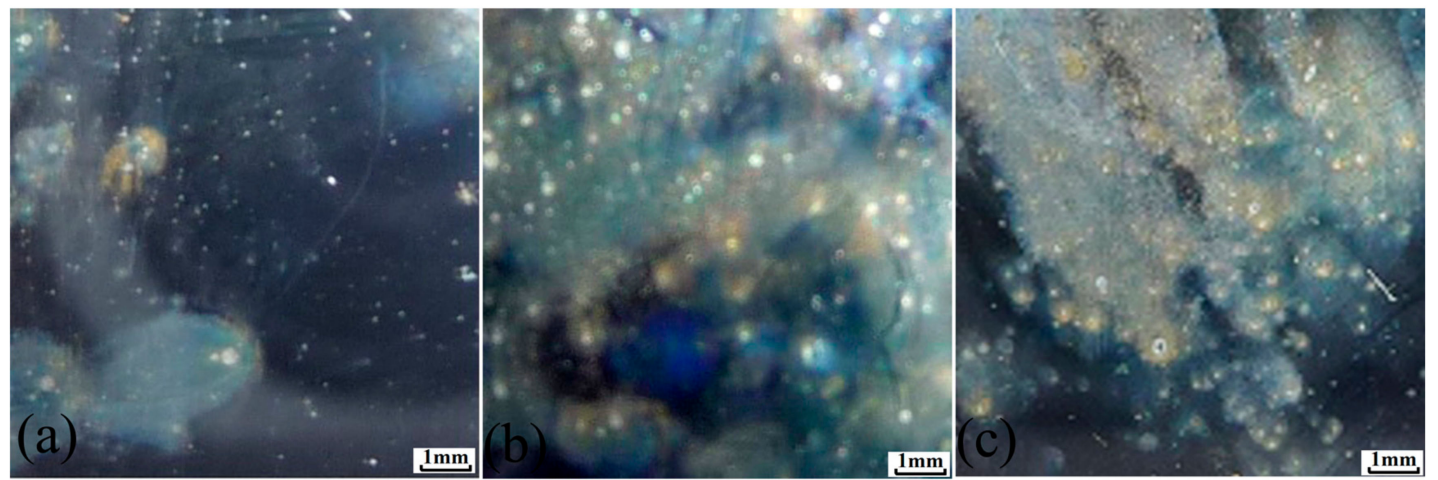

Figure 10. Corrosion macroscopic morphology of the $X 70$ steel after immersion for $30 \mathrm{~min}$ in $0.1 \mathrm{~mol} / \mathrm{L}$ $\mathrm{NaCl}$ solution at: (a) $0.1 \mathrm{MPa}$; (b) $5 \mathrm{MPa}$ and (c) $10 \mathrm{MPa}$.

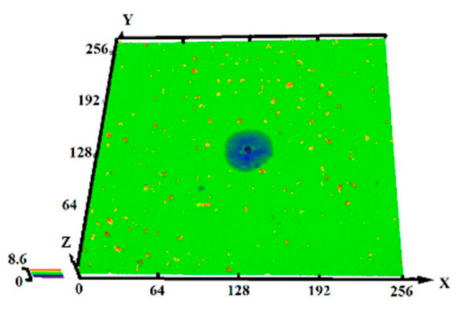

(a)

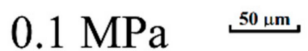

Figure 11. Typical 3D morphology of corrosion pits after immersion for $30 \mathrm{~min}$ in $0.1 \mathrm{~mol} / \mathrm{L} \mathrm{NaCl}$ solution at: (a) $0.1 \mathrm{MPa}$; (b) $5 \mathrm{MPa}$ and (c) $10 \mathrm{MPa}$. 


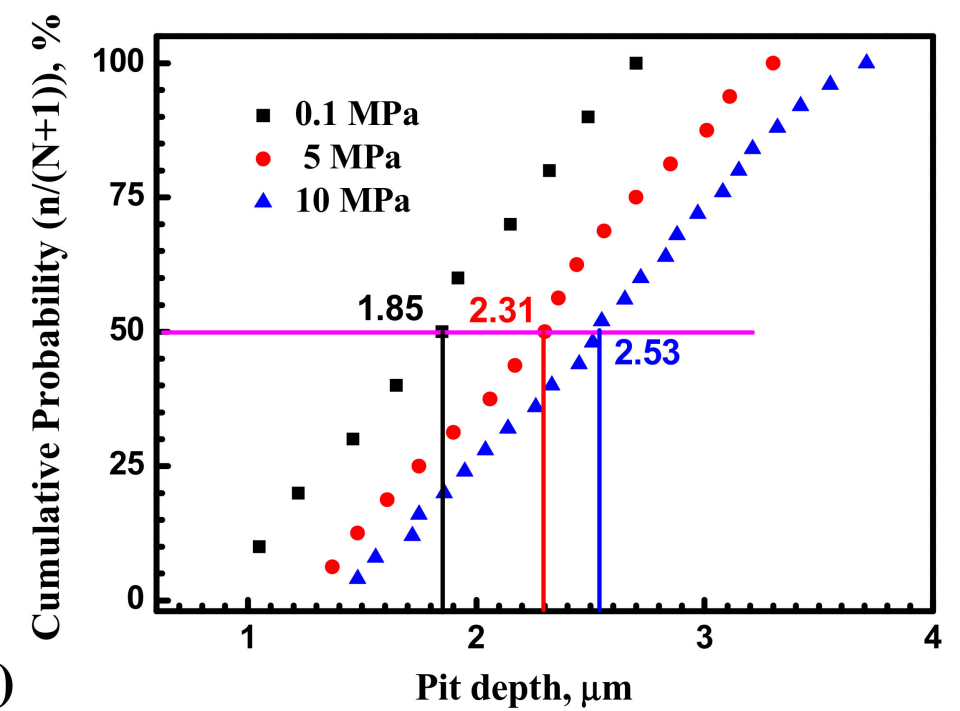

(a)

Pit depth, $\mu \mathrm{m}$

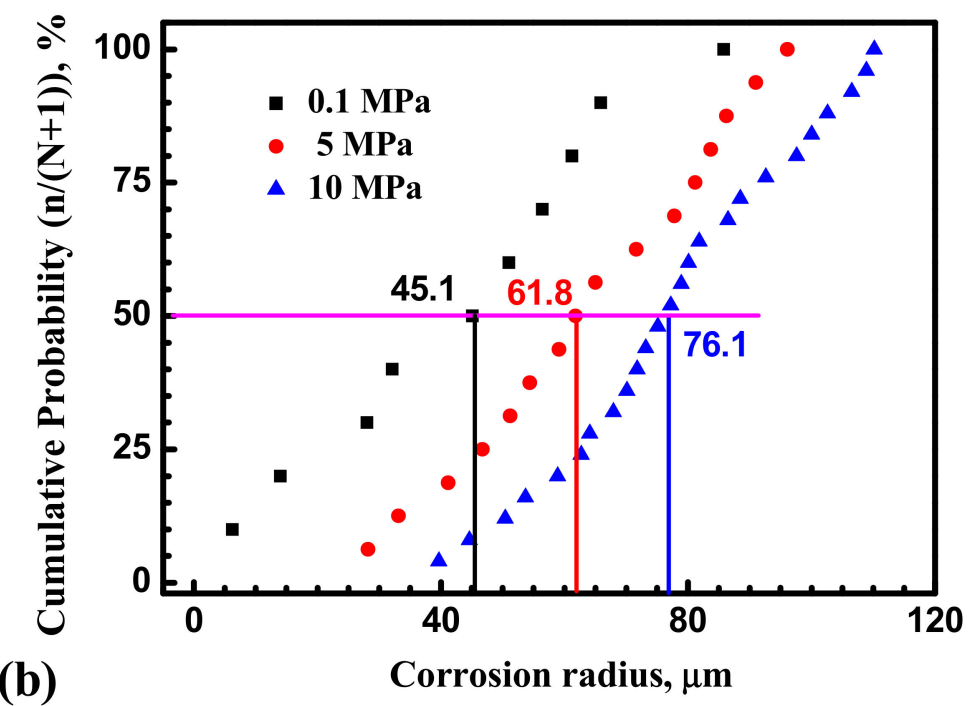

Figure 12. The $3 \mathrm{D}$ sizes of corrosion pits of the $X 70$ steel at $0.1 \mathrm{MPa}, 5 \mathrm{MPa}$ and $10 \mathrm{MPa}$ after $30 \mathrm{~min}$ immersion in $0.1 \mathrm{~mol} / \mathrm{L} \mathrm{NaCl}$ solution: (a) Pit depth; (b) Corrosion radius.

\section{Discussion}

\subsection{Hydrostatic Pressure Effect on Metastable Pit Initiation}

Previous researchers analyzed metastable pit by counting the generation frequency of transient current peaks. Williams [30,31] reported a linear relationship between metastable and stable pitting.

Figures 3 and 5 show a larger number of metastable pits with hydrostatic pressure. Relatively higher frequency of metastable pit formation could be explained based on the ability of inclusions to dissolve and form weaker passive film [13,14]. Beccaria and Sun [21,22] reported that high hydrostatic pressure can promote the adsorption of $\mathrm{Cl}^{-}$on metal surface, especially in inclusion site. Increased $\mathrm{Cl}^{-}$ can enhance dissolution of the inclusions. In addition, weaker passive film can be formed at inclusion position with increasing $\mathrm{Cl}^{-}$content. Thus, many more nucleation points would be generated at inclusions site. The frequency of metastable pitting initiation is increased with hydrostatic pressure. As shown in Figure 10, the number of pits on the X70 steel surface is significantly higher at $10 \mathrm{MPa}$. 


\subsection{Hydrostatic Pressure Effect on Metastable Pit Growth}

Metastable pitting growth rate is affected by the environment around pitting. Passive film structure and stress conditions around the pit are quite complex [6,15]. Figures 6 and 7 show that the metastable pits developed at higher hydrostatic pressure (10 MPa) are accompanied with higher peak current and longer lifetime. It can be concluded that higher hydrostatic pressure promotes anodic dissolution around and inside the pit site in the X70 steel. Figure 8 clearly shows that higher hydrostatic pressure increases calculated radius of metastable pitting. According to the results, metastable pit current is a measure of its growth rate. Similar to corrosion rate of steel, higher current peak and longer lifetime at higher hydrostatic pressure indicate higher corrosion rate.

Previous work found that localized stress around pitting can significantly affect pit growth rate [23]. Hydrostatic pressure can affect the electrochemical activity of deformed metal. According to Gutman's theory $[10,11]$, the anodic dissolution non-equilibrium kinetic equation can be defined as:

$$
i_{p}=i_{a} \exp \frac{\Delta p V_{m}}{R T}
$$

Here, $i_{p}$ is the anodic dissolution current, $i_{a}$ is the anodic current of an unstressed sample, $p$ is the spherical part of macroscopic stress tensor (i.e., hydrostatic pressure) depending on the applied load and $V_{m}$ is the molar volume of the substance [11,32].

According to Yang et al., stress concentration is induced by corrosion pitting during loading with hydrostatic pressure. Then corrosion will preferentially dissolve the pitting site. At the same time, stress concentration at corrosion pits increases with hydrostatic pressure [10]. It can further promote steel anodic activity around the pit.

In addition, Figure 13 shows the impedance spectra at different hydrostatic pressure. As shown in Figure 13, it is remarkable that the diameters of semicircles decrease with hydrostatic pressure, the impedance markedly decrease with hydrostatic pressure at low frequencies region indicating that electrochemical process is accelerated by hydrostatic pressure after $30 \mathrm{~min}$ immersion. Generally, for EIS measured on bare low alloy steel samples, the charge transfer resistance is the only time constant [33]. Thus, hydrostatic pressure decreases the charge transfer resistance and increases the dissolution rate within the cavities. As shown in Figure 12, the radius of the X70 steel surface pits is significantly larger at $10 \mathrm{MPa}$.

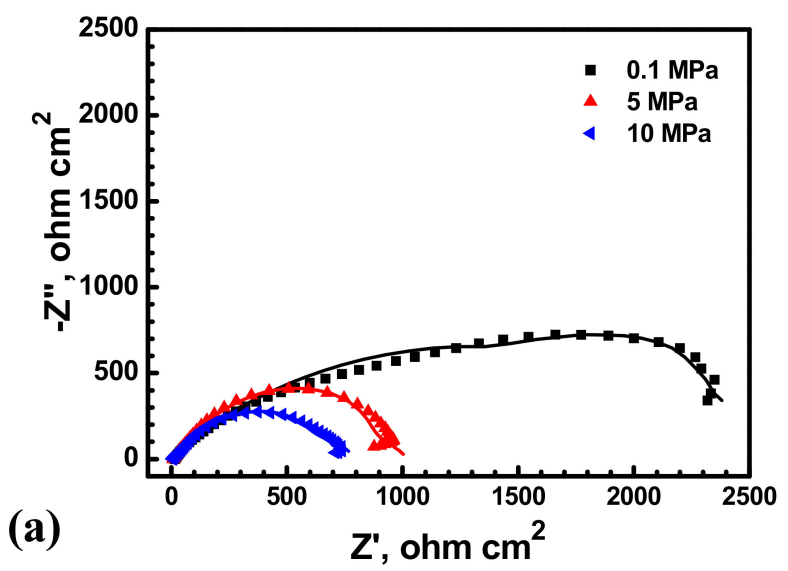

Figure 13. Cont. 

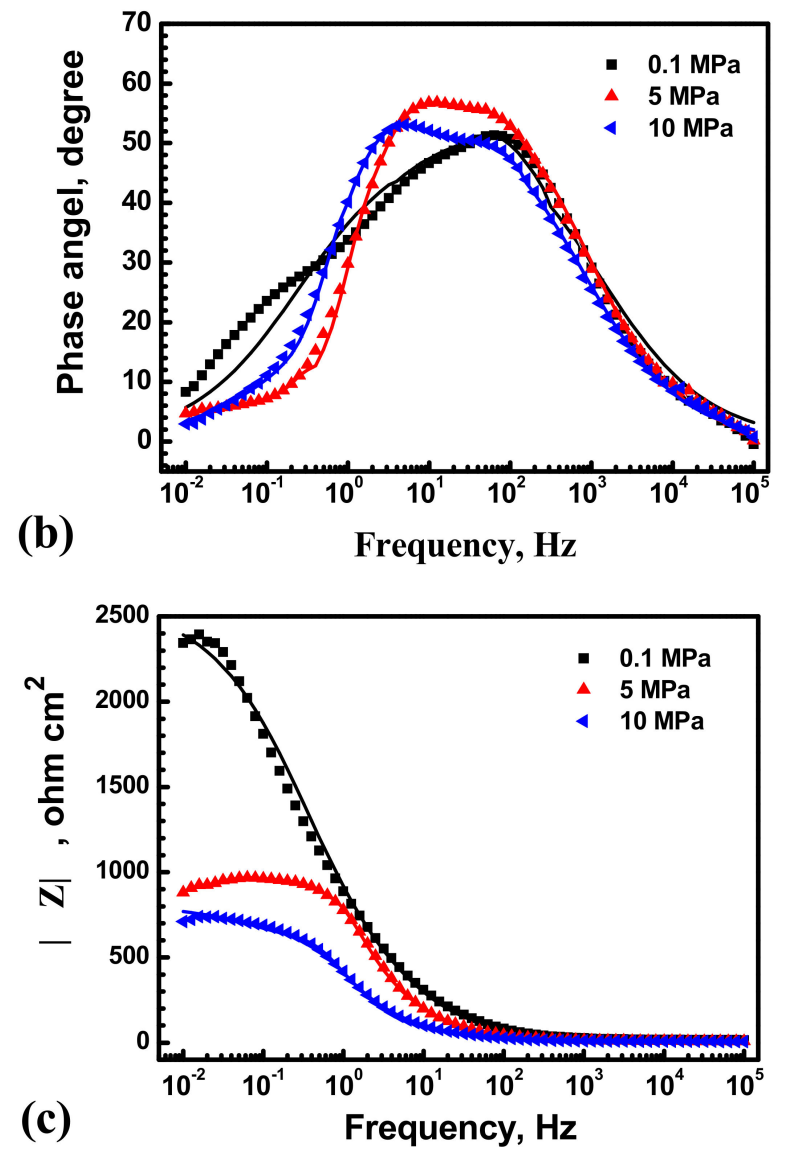

Figure 13. Impedance spectra of the $X 70$ steel measured at the open circuit potential in $0.1 \mathrm{~mol} / \mathrm{L}$ $\mathrm{NaCl}$ solution at $0.1 \mathrm{MPa}, 5 \mathrm{MPa}$ and $10 \mathrm{MPa}$. Solid lines represent fitted results. (a) Nyquist plot; (b) Bode-Phase angle plot; (c) Bode-impedance plot.

\subsection{Hydrostatic Pressure Effect on Metastable Pitting Stabilization}

Higher hydrostatic pressure would result in higher $\mathrm{i} \times \mathrm{r}$ value, as shown in Figure 10. It can be concluded that metastable pitting developed at higher hydrostatic pressure of $10 \mathrm{MPa}$ results in much higher stability products than at lower hydrostatic pressure of $0.1 \mathrm{MPa}$. Therefore, at $10 \mathrm{MPa}$, metastable pitting stabilization is easier than at $0.1 \mathrm{MPa}$.

Williams et al. $[30,31]$ reported that pitting corrosion susceptibility is directly related to the frequency of metastable pitting formation. Pitting resistance dependence on the frequency of metastable pitting formation can be expressed as:

$$
\Lambda=\lambda \exp \left(-\mu \tau_{c}\right)
$$

Here, $\Lambda$ is the rate of formation of stable pitting, $\lambda$ is the rate of formation of metastable pitting, $\mu$ is the repassivation probability of metastable pitting, and $\tau_{\mathrm{c}}$ is the critical time when pits are considered stable $[34,35]$.

Metastable pit frequency results (Figure 6) confirm that higher hydrostatic pressure significantly improves the frequency of metastable pitting formation. It can be concluded that increasing hydrostatic pressure would lead to decreased corrosion resistance of the X70 steel. The frequency of stable pit formation increases with hydrostatic pressure.

Besides, individual metastable current transients indicated that hydrostatic pressure speeds up dissolution kinetics and promotes pitting stabilization. Thus, hydrostatic pressure would improve pitting corrosion susceptibility of the X70 steel. This is consistent with the result of corrosion tests, 
which revealed that hydrostatic pressure increases the number of pits in Figure 12. This was verified by evaluating metastable pitting to predict pitting corrosion resistance.

\section{Conclusions}

In this paper, the hydrostatic pressure effects on pitting initiation, metastable pitting and propagation in X70 steel have been investigated by evaluating metastable pitting events and immersion tests. The results could be summarized as follows:

(1) Potentiodynamic measurements indicated that increasing hydrostatic pressure decreases the breakdown potential and leads to reduced transpassivity region.

(2) Hydrostatic pressure can promote the adsorption of $\mathrm{Cl}^{-}$on metal surface. Potentiostatic measurement indicated that the rate of metastable pit formation in the X70 steel increased with hydrostatic pressure, indicating that the pitting generation rate was increased. EIS results indicate Hydrostatic pressure decreases the charge transfer resistance and increases the dissolution rate within the cavities. The results also revealed that increasing hydrostatic pressure leads to an increase in the average values of metastable pitting peak current, pit radius and pit lifetime. Hydrostatic pressure improves the probability of metastable pits transition to stability. This means that hydrostatic pressure promotes metastable pitting initiation and propagation.

(3) Metastable pit measurement and corrosion tests both indicated that pitting initiation and propagation are accelerated by hydrostatic pressure. Result validity is verified by evaluating metastable pitting to predict pitting corrosion resistance.

Acknowledgments: This project was supported by the National Basic Research Program of China under grant No. 2014CB643301 and the National Nature Science Foundation of China under grants 51371035 and 51371037.

Author Contributions: Jinxu Li and Zixuan Yang conceived and designed the experiments; Zixuan Yang and Bo Kan performed the experiments; Jinxu Li and Zixuan Yang analyzed the data; Yanjing Su, Lijie Qiao and Alex A. Volinsky contributed reagents/materials/analysis tools; Zixuan Yang wrote the paper.

Conflicts of Interest: The authors declare no conflict of interest.

\section{References}

1. Traverso, P.; Canepa, E. A review of studies on corrosion of metals and alloys in deep-sea environment. Ocean. Eng. 2014, 87, 10-15. [CrossRef]

2. Gupta, R.K.; Sukiman, N.L.; Cavanaugh, M.K.; Hutchinson, C.R.; Birbilis, N. Metastable pitting characteristics of aluminium alloys measured using current transients during potentiostatic polarization. Electrochim. Acta 2012, 66, 245-254. [CrossRef]

3. Tian, W.M.; Du, N.; Li, S.M.; Chen, S.B.; Wu, Q.Y. Metastable pitting corrosion of 304 stainless steel in 3.5\% $\mathrm{NaCl}$ solution. Corros. Sci. 2014, 85, 372-379. [CrossRef]

4. Beccaria, A.M.; Poggi, G. Influence of hydrostatic pressure on pitting of aluminium in sea water. Br. Corros. J. 1985, 20, 183-186. [CrossRef]

5. Beccaria, A.M. The effect of hydrostatic pressure on the corrosion of nickel in slightly alkaline solutions containing $\mathrm{Cl}^{-}$ions. Corros. Sci. 1989, 29, 408-416. [CrossRef]

6. Beccaria, A.M.; Poggi, G. The effect of salt concentration on nickel corrosion behaviour in slightly alkaline solutions at different hydrostatic pressures. Corros. Sci. 1993, 34, 989-1005. [CrossRef]

7. Beccaria, A.M.; Poggi, G. Influence of passive film composition and sea water pressure on resistance to localized corrosion of some stainless steels in sea water. Br. Corros. J. 1995, 30, 283-286. [CrossRef]

8. Hamdy, A.S.; Beccaria, A.M. Corrosion protection of AA6061 T6 by fluoropolymer coatings in $\mathrm{NaCl}$ solution. Surf. Coat. Technol. 2002, 155, 176-183. [CrossRef]

9. Zhang, T.; Yang, Y.G.; Shao, Y.W. A stochastic analysis of the effect of hydrostatic pressure on the pit corrosion of Fe-20Cr alloy. Electrochim. Acta 2009, 54, 3915-3922. [CrossRef]

10. Yang, Y.G.; Zhang, T.; Shao, Y.W.; Meng, G.Z.; Wang, F.H. Effect of hydrostatic pressure on the corrosion behaviour of Ni-Cr-Mo-V high strength steel. Corros. Sci. 2010, 52, 2697-2706. [CrossRef]

11. Yang, Y.G.; Zhang, T.; Shao, Y.W. New understanding of the effect of hydrostatic pressure on the corrosion of $\mathrm{Ni-Cr-Mo-V} \mathrm{high} \mathrm{strength} \mathrm{steel.} \mathrm{Corros.} \mathrm{Sci.} \mathrm{2013,} \mathrm{73,} \mathrm{250-261.} \mathrm{[CrossRef]}$ 
12. Pistorius, P.C.; Burstein, G.T. Metastable pitting corrosion of stainless steel and the transition to stability. Philos. Trans. R. Soc. Lond. A 1992, 341, 531-559. [CrossRef]

13. Abbasi Aghuy, A.; Zakeri, M.; Moayed, M.H.; Mazinani, M. Effect of grain size on pitting corrosion of 304L austenitic stainless steel. Corros. Sci. 2015, 94, 368-376. [CrossRef]

14. Mahdi, E.; Rauf, A.; Eltai, E.O. Effect of temperature and erosion on pitting corrosion of X100 steel in aqueous silica slurries containing bicarbonate and chloride content. Corros. Sci. 2014, 83, 48-58. [CrossRef]

15. Guan, L.; Zhang, B.; Yong, X.P. Effects of cyclic stress on the metastable pitting characteristic for 304 stainless steel under potentiostatic polarization. Corros. Sci. 2015, 93, 80-89. [CrossRef]

16. Gholami, M.; Hoseinpoor, M.; Moayed, M.H. A statistical study on the effect of annealing temperature on pitting corrosion resistance of 2205 duplex stainless steel. Corros. Sci. 2015, 94, 156-164. [CrossRef]

17. Amin, M.A. Metastable and stable pitting events on Al induced by chlorate and perchlorate anions-Polarization, XPS and SEM studies. Electrochim. Acta 2009, 54, 1857-1863. [CrossRef]

18. Jeon, S.H.; Kim, S.T.; Choi, M.S. Effects of cerium on the compositional variations in and around inclusions and the initiation and propagation of pitting corrosion in hyperduplex stainless steels. Corros. Sci. 2013, 75, 367-375. [CrossRef]

19. Jeon, S.H.; Kim, S.T.; Lee, I.S. Effects of sulfur addition on pitting corrosion and machinability behavior of super duplex stainless steel containing rare earth metals: Part 2. Corros. Sci. 2010, 52, 3537-3547. [CrossRef]

20. Jeon, S.H.; Kim, S.T.; Lee, I.S. Effects of copper addition on the formation of inclusions and the resistance to pitting corrosion of high performance duplex stainless steels. Corros. Sci. 2011, 53, 1408-1416. [CrossRef]

21. Sun, H.J.; Liu, L.; Li, Y.; Wang, F.H. Effect of Hydrostatic Pressure on the Corrosion Behavior of a Low Alloy Steel. J. Electrochem. Soc. 2013, 160, C89-C96. [CrossRef]

22. Sun, H.J.; Liu, L.; Li, Y.; Wang, F.H. The performance of Al-Zn-In-Mg-Ti sacrificial anode in simulated deep water environment. Corros. Sci. 2013, 77, 77-87. [CrossRef]

23. Zheng, S.Q.; Li, C.Y.; Qi, Y.M. Mechanism of (Mg, Al, Ca)-oxide inclusion-induced pitting corrosion in 316L stainless steel exposed to sulphur environments containing chloride ion. Corros. Sci. 2013, 67, 20-31. [CrossRef]

24. Daufin, G.; Pagetti, J.; Labbe, J.P. Pitting initiation on stainless steel: Electrochemical and micrographic aspects. Corrosion 1985, 41, 533-539. [CrossRef]

25. Yang, Z.; Kan, B.; Li, J.; Su, Y.; Qiao, L.; Volinsky, A.A. Pitting Initiation and Propagation of X70 Pipeline Steel Exposed to Chloride-Containing Environments. Materials 2017, 10, 1076. [CrossRef] [PubMed]

26. Tang, Y.M.; Zuo, Y.; Wang, J.N. The metastable pitting potential and its relation to the pitting potential for four materials in chloride solutions. Corros. Sci. 2014, 80, 111-119. [CrossRef]

27. Tang, Y.M.; Zuo, Y. The metastable pitting of mild steel in bicarbonate solutions. Mater. Chem. Phys. 2004, 88, 221-226. [CrossRef]

28. Liu, J.; Zhang, T.; Meng, G.Z. Effect of pitting nucleation on critical pitting temperature of 316L stainless steel by nitric acid passivation. Corros. Sci. 2015, 91, 232-244. [CrossRef]

29. Zhang, F.; Pan, J.S.; Lin, C.J. Localized corrosion behaviour of reinforcement steel in simulated concrete pore solution. Corros. Sci. 2009, 51, 2130-2138. [CrossRef]

30. Williams, D.E.; Stewart, J.; Balkwill, P.H. The nucleation, growth and stability of micropits in stainless steel. Corros. Sci. 1994, 36, 1213-1215. [CrossRef]

31. Williams, D.E.; Westcott, C.; Fleischmann, M. Stochastic Models of Pitting Corrosion of Stainless Steels. J. Electrochem. Soc. 1985, 132, 1796. [CrossRef]

32. Gutman, E.M. Mechanochemistry of Solid Surfaces; World Scientific: Singapore, 1994.

33. Yan, M.C.; Xu, J.; Yu, L.B. EIS analysis on stress corrosion initiation of pipeline steel under disbonded coating in near-neutral pH simulated soil electrolyte. Corros. Sci. 2016, 110, 23-34.

34. Naghizadeh, M.; Nakhaie, D.; Zakeri, M. The effect of dichromate ion on the pitting corrosion of AISI 316 stainless steel Part II: Pit initiation and transition to stability. Corros. Sci. 2015, 94, 420-427. [CrossRef]

35. Frankel, G.S.; Stockert, L.; Hunkeler, F.; Boehni, H. Metastable pitting of stainless steel. Corrosion 1987, 43, 429-436. [CrossRef]

(C) 2017 by the authors. Licensee MDPI, Basel, Switzerland. This article is an open access article distributed under the terms and conditions of the Creative Commons Attribution (CC BY) license (http:/ / creativecommons.org/licenses/by/4.0/). 